\title{
MedDRA Body System or Organ Class
} Code

National Cancer Institute

\section{Source}

National Cancer Institute. MedDRA Body System or Organ Class Code. NCI Thesaurus.

Code $C 117040$.

A coded value specifying the type of body system or org an class from the Medical Dictionary for Regulatory Activities (MedDRA). 